\title{
A STUDY ABOUT PERCEPTION OF PEOPLE REGARDING ANIMAL BITE IN URBAN AREA OF DEHRADUN
}

\author{
Puneet Ohri', Kajal Jain², Rashmi Kumari³, Sudhir Kumar Gupta ${ }^{4}$
}

${ }^{1}$ Associate Professor, Department of Community Medicine, Shri Guru Ram Rai Institute of Medical and Health Sciences, Dehradun. ${ }^{2}$ Associate Professor, Department of Community Medicine, Shri Guru Ram Rai Institute of Medical and Health Sciences, Dehradun. ${ }^{3}$ Assistant Professor, Department of Community Medicine, Shri Guru Ram Rai Institute of Medical and Health Sciences, Dehradun. ${ }^{4}$ Professor \& HOD, Department of Community Medicine, Shri Guru Ram Rai Institute of Medical and Health Sciences, Dehradun.

\begin{abstract}
Animal bite is neglected problem in India. Many animal bite cases turn out to be rabies, which is a disease of worldwide importance. Out of the estimated 55,000 deaths worldwide due to rabies, 20,000 deaths occur in India alone (2 per lac population at risk). At present Indian and State Government resources are mainly focussing on the Anti-Rabies Therapy. Thus the people at large have no or little knowledge from community about the various aspects of rabies and its treatment.
\end{abstract}

\section{OBJECTIVES}

The present study is an effort to understand the level of knowledge, their beliefs and perception about the animal bite. To study the people's preparedness in case of animal bite.

\section{METHODS}

Cross sectional study conducted in field practice area of Urban Health Centre, Bhandari Bagh, Dehradun, from April 2013 to June 2013. The total population study area (Bhandari Bagh) is 12,000 and that is in 2400 families. This is spread out in 12 colonies/Mohallas; $10 \%$ of the total families, i.e. 240 were taken by systematic random sampling method. Interview of available adult member of the family was taken using semi-structured pre-tested questionnaire. The information on Knowledge, Attitude and Practices (KAP) related to animal bite was collected.

\section{RESULTS}

A $45.5 \%$ people perception was that the person becomes insane after animal bite; $83.9 \%$ people knew that animal bite is the mode of transmission; $77.52 \%$ respondents believed that the dogs transmit the rabies, but knowledge regarding other animals transmitting rabies was limited; 55\% people said they should consult doctor after animal bite and $18.33 \%$ of persons knew about usage of Anti Rabies Vaccine (ARV).

\section{DISCUSSION}

Old beliefs (9.58\% believe in witchcraft, $15.1 \%$ believe there is spread of poison after animal bite) and practices (Applying turmeric and chillies $57.9 \%$ ) exist in the community. Knowledge about animals transmitting rabies other than dog was also yet inadequate. So policy needs to focus to impart knowledge by the health workers and doctors to change their belief and practices.

\section{KEYWORDS}

Rabies, ARV, KAP, IEC, IPC.

HOW TO CITE THIS ARTICLE: Ohri P, Jain K, Kumari R, et al. A study about perception of people regarding animal bite in urban area of Dehradun. J. Evolution Med. Dent. Sci. 2016;5(17):846-849, DOI: 10.14260/jemds/2016/196

\section{INTRODUCTION}

Animal bite is neglected problem in India. Many animal bite cases turn out to be rabies, which is a disease of worldwide importance. Although many countries have eliminated this disease due to geographical barriers and strong policy implementations, but India seems far away from achieving this. Australia, China (Taiwan), Cyprus, Iceland, Ireland, Japan, Malta, New Zealand, UK and the islands of western pacific are all free of the disease. ${ }^{1}$ Out of the estimated 55,000 deaths worldwide due to rabies, 20,000 deaths occur in India alone. ${ }^{2}$ ( 2 per lac population at risk). It has been seen that the information regarding Anti-Rabies Therapy is adequate, but the people have no clear knowledge about the various aspects of rabies and wound management as seen in different studies.

Financial or Other, Competing Interest: None.

Submission 05-01-2016, Peer Review 02-02-2016,

Acceptance 08-02-2016, Published 27-02-2016.

Corresponding Author:

Dr. Kajal Jain,

Department of Community Medicine,

Patel Nagal, Dehradun-248001, Uttarakhand.

E-mail: dr_kajal_jain@yahoo.ie

DOI: 10.14260/jemds/2016/196
One of the studies show that $82 \%$ people believed in applying cowdung, while $60 \%$ felt that leaves can be applied at the wound following dog bite. ${ }^{3}$

\section{OBJECTIVES}

1. The present study is an effort to understand the level of knowledge, their beliefs and perception about the animal bite.

2. To study the peoples preparedness in case of animal bite.

\section{MATERIAL AND METHODS}

This is a cross-sectional study conducted in field practice area of Urban Health Training Centre, Bhandari Bagh, Dehradun, from April 2013 to June 2013. The total population of study area (Bhandari Bagh) is 12,000 and number of total families 2400. It included 12 colonies/Mohallas; $10 \%$ of the total families, i.e. 240 were taken by systematic random sampling method. Interview of available adult member of the family was taken using semi-structured pre-tested questionnaire. The information on knowledge, attitude and practices related to dog bite was collected. 
If the family is not cooperative or for some reason the interview could not be conducted, the member of adjacent family was interviewed.

\begin{tabular}{|c|c|c|}
\hline \multicolumn{3}{|c|}{$\mathbf{N = 2 4 0}$ \& Multiple Response =258 } \\
\hline Variables & Numbers & Percentage \\
\hline Insanity & 107 & 45.58 \\
\hline Rabies & 44 & 18.33 \\
\hline Spread of poison & 37 & 15.41 \\
\hline Infection & 9 & 3.75 \\
\hline Death & 3 & 1.25 \\
\hline Other & 7 & 2.91 \\
\hline Don't know & 51 & 21.25 \\
\hline \multicolumn{2}{|c|}{ Table 1: Perception of People regarding } \\
Effect of Animal Bite \\
\hline
\end{tabular}

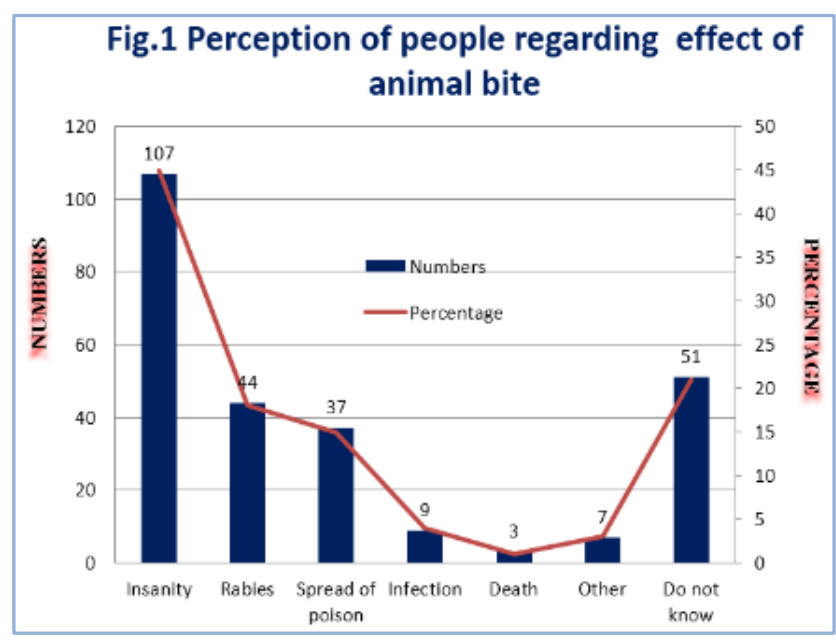

\begin{tabular}{|c|c|c|c|}
\hline Variables & $\begin{array}{c}\text { Male } \\
\text { N (\%) }\end{array}$ & $\begin{array}{c}\text { Female } \\
\text { N (\%) }\end{array}$ & Total \\
\hline Animal bite & $146(83.9 \%)$ & $55(83.3 \%)$ & $201(83.9 \%)$ \\
\hline Sneezing & $18(10.3 \%)$ & $8(12.2 \%)$ & $26(10.9 \%)$ \\
\hline Don't Know & $7(4.1 \%)$ & $2(3.0 \%)$ & $9(3.9 \%)$ \\
\hline Others & $3(1.7 \%)$ & $1(1.5 \%)$ & $4(1.8 \%)$ \\
\hline Total & $\begin{array}{c}\mathbf{1 7 4} \\
(\mathbf{1 0 0 . 0 \% )}\end{array}$ & $\begin{array}{c}\mathbf{6 6} \\
(\mathbf{1 0 0 . 0} \%)\end{array}$ & $\begin{array}{c}\mathbf{2 4 0} \\
(\mathbf{1 0 0 . 0} \%)\end{array}$ \\
\hline \multicolumn{4}{|c|}{ Table 2: Knowledge regarding Mode of } \\
Transmission of Rabies \\
\hline
\end{tabular}

$\chi^{2}=0.280, \mathrm{df}=3, \mathrm{P}>0.05$

\begin{tabular}{|c|c|c|}
\hline \multicolumn{3}{|c|}{$\mathrm{N}=240$ \& Multiple Response $=433$} \\
\hline $\begin{array}{c}\text { Animal Transmitting } \\
\text { Rabies }\end{array}$ & Number & Percentage \\
\hline Dog & 186 & 77.52 \\
\hline Monkey & 92 & 38.33 \\
\hline Cat & 57 & 23.75 \\
\hline Mouse & 15 & 6.25 \\
\hline Fox & 9 & 3.75 \\
\hline Horse & 4 & 1.66 \\
\hline Others* & 14 & 5.83 \\
\hline \multicolumn{3}{|l|}{ Animal not transmitting Rabies } \\
\hline Snake & 11 & 4.58 \\
\hline Lizard & 4 & 1.66 \\
\hline Others** & 6 & 2.5 \\
\hline Don't Know & 35 & 14.58 \\
\hline \multicolumn{3}{|c|}{$\begin{array}{l}\text { Table 3: Knowledge regarding Animals } \\
\text { Transmitting Rabies }\end{array}$} \\
\hline
\end{tabular}

Others * animals included in group transmitting rabies are rabbit, cow, pig, bat, lion, bear, goat.

Others ${ }^{* *}$ in group of animal not transmitting rabies include scorpion, environmental pollution, mosquito and other insects,

\begin{tabular}{|c|c|c|c|c|c|c|c|c|}
\hline $\begin{array}{c}\text { Literacy } \\
\text { Status }\end{array}$ & $\begin{array}{c}\text { Doctors } \\
\text { N (\%) }\end{array}$ & $\begin{array}{c}\text { Anti- } \\
\text { Rabies } \\
\text { Vaccines } \\
\text { (ARV) } \\
\mathbf{N}(\%)\end{array}$ & $\begin{array}{c}\text { Tetanus } \\
\text { Toxoid } \\
\text { (TT) } \\
\mathbf{N}(\%)\end{array}$ & $\begin{array}{c}\text { Witchcraft } \\
\mathbf{N}(\%)\end{array}$ & $\begin{array}{c}\text { Witchcraft \& } \\
\text { Consult } \\
\text { Doctor } \\
\text { N (\%) }\end{array}$ & $\begin{array}{c}\text { Witchcraft } \\
\text { \& ARV } \\
\text { N (\%) }\end{array}$ & $\begin{array}{c}\text { Others } \\
\text { N (\%) }\end{array}$ & $\begin{array}{c}\text { Don't } \\
\text { Know } \\
\text { N (\%) }\end{array}$ \\
\hline Illiterate & $24(18.2 \%)$ & $7(15.9 \%)$ & $0(0.0 \%)$ & $10(43.5 \%)$ & $9(42.9 \%$ & $2(22.2 \%)$ & $0(0.0 \%)$ & $2(40.0 \%)$ \\
\hline Up to Primary & $48(36.4 \%)$ & $8(18.2 \%)$ & $0(0.0 \%)$ & $10(43.5 \%)$ & $7(33.3 \%)$ & $4(44.4 \%)$ & $1(20.0)$ & $1(20.0 \%)$ \\
\hline Up to Middle & $26(19.7 \%)$ & $10(22.7 \%)$ & $0(0.0 \%)$ & $2(8.7 \%)$ & $4(19.0 \%)$ & $1(11.1 \%)$ & $2(40.0 \%)$ & $1(20.0 \%)$ \\
\hline High School & $20(15.2 \%)$ & $11(25.0 \%)$ & $1(50.0 \%)$ & $1(4.3 \%)$ & $0(0.0 \%)$ & $1(11.1 \%)$ & $0(0.0 \%)$ & $0(0.0 \%)$ \\
\hline Intermediate & $12(9.1 \%)$ & $6(13.6 \%)$ & $1(50.0 \%)$ & $0(0.0 \%)$ & $1(4.8 \%)$ & $1(11.1 \%)$ & $1(20.0 \%)$ & $1(20.0 \%)$ \\
\hline $\begin{array}{c}\text { Professional } \\
\text { Diploma }\end{array}$ & $1(0.8 \%)$ & $1(2.3 \%)$ & $0(0.0 \%)$ & $0(0.0 \%)$ & $0(0.0 \%)$ & $0(0.0 \%)$ & $0(0.0 \%)$ & $0(0.0 \%)$ \\
\hline Degree & $1(0.8 \%)$ & $1(2.3 \%)$ & $0(0.0 \%)$ & $0(0.0 \%)$ & $0(0.0 \%)$ & $0(0.0 \%)$ & $1(20.0 \%)$ & $0(0.0 \%)$ \\
\hline Total & $\mathbf{1 3 2}$ & $\mathbf{4 4 4}$ & $\mathbf{2}$ & $\mathbf{2 3}$ & $\mathbf{2 0}$ & $\mathbf{9}$ & $\mathbf{5}$ & $\mathbf{5}$ \\
\hline Percentage & $\mathbf{5 5 \%}$ & $\mathbf{1 8 . 3 3 \%}$ & $\mathbf{0 . 8 3 \%}$ & $\mathbf{9 . 5 8 \%}$ & $\mathbf{8 . 3 3 \%}$ & $\mathbf{3 . 7 5 \%}$ & $\mathbf{2 . 0 8 \%}$ & $\mathbf{2 . 0 8 \%}$ \\
\hline \multicolumn{7}{|c|}{ Table 4: Perception about Management of Animal Bite } \\
\hline
\end{tabular}

$\mathrm{X}^{2}=56.160, \mathrm{df}=42, \mathrm{P}<0.05$

Remove Test 


\begin{tabular}{|c|c|c|c|}
\hline \multirow{2}{*}{ Variables } & Male N (\%) & Female N (\%) & Total N (\%) \\
\cline { 2 - 4 } & $9(5.2 \%)$ & $1(1.5 \%)$ & $10(4.2 \%)$ \\
\hline Only water & $21(12.1 \%)$ & $5(7.6 \%)$ & $26(10.8 \%)$ \\
\hline Wash with soap \& water & $10(5.7 \%)$ & $6(9.1 \%)$ & $16(6.7 \%)$ \\
\hline Medication & $8(4.6 \%)$ & $4(6.1 \%)$ & $12(5.0 \%)$ \\
\hline $\begin{array}{c}\text { Both water soap \& } \\
\text { medication }\end{array}$ & $97(55.7 \%)$ & $42(63.6 \%)$ & $139(57.9 \%)$ \\
\hline Chilli \& turmeric & $16(9.2 \%)$ & $5(7.6 \%)$ & $21(8.8 \%)$ \\
\hline $\begin{array}{c}\text { Both chilli-turmeric \& wash } \\
\text { the wound with soap \& water }\end{array}$ & $13(7.5 \%)$ & $3(4.5 \%)$ & $16(6.7 \%)$ \\
\hline Others & $\mathbf{1 7 4}$ & $\mathbf{6 6}$ & $\mathbf{2 4 0}$ \\
\hline Total & Table 5: Knowledge regarding Management at Wound Site & \\
\hline
\end{tabular}

$\chi^{2}=4.707, \mathrm{df}=6, \mathrm{P}>0.05$

\section{RESULTS}

In Table No. 1 maximum number $45.5 \%$ of people said that person bitten by animal will go insane; $18.3 \%$ said animal bite will cause rabies and $15.4 \%$ said there will be spread of poison; $21.2 \%$ did not knew what will happen after animal bite. Others were $2.91 \%$ and these included hydrophobia, restlessness, unconsciousness, nervous breakdown, bark like dog, thirst.

In Table No. 2 out of the total males (174) about 83.9\% said that rabies was transmitted by animal bite, $10.3 \%$ by sneezing, $4.1 \%$ does not know the exact mode of transmission. Among the total females (66) about $83.3 \%$ said that rabies were transmitted by animal bite, $12.2 \%$ by sneezing and $3 \%$ does not know the exact mode of transmission. Thus animal bite is the commonest mode of transmission $83.9 \%$, sneezing $10.9 \%$ and $3.9 \%$ does not know the exact mode of transmission.

In Table No. 3, the knowledge of people regarding animals transmitting rabies is $77.52 \%$ by dog followed by monkey $38.33 \%$ and cat $23.75 \%$. Others* included in this group are rabbit, cow, pig, bat, lion, bear, goat.

There were few respondents who said that rabies is transmitted by some modes, which are not responsible for transmission of rabies. Snake $4.58 \%$, Lizard $1.66 \%$ and

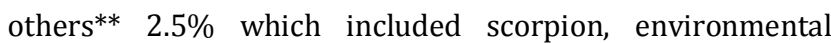
pollution, mosquito and other insects; $14.58 \%$ of individuals had no knowledge regarding transmission of rabies.

In Table No. 4, people's perception regarding management of animal bite with witchcraft is higher in lower education status. Witchcraft in illiterate and up to primary was $43.5 \%$ each, witchcraft and consult doctor was $42.9 \%$ among illiterate and $33.3 \%$ up to primary. Witchcraft and ARV in illiterate is $22.2 \%$ and up to primary was $44.1 \%$. Management of animal bite by consulting doctor or by ARV was seen among all education group, although higher percentage was seen in lower education groups.

In Table No. 5, both male $55.7 \%$ and female $63.6 \%$ still believed in applying chilli and turmeric at the wound site. A $10.8 \%$ were having adequate knowledge of washing the wound with water and soap, though males $12.1 \%$ had higher knowledge compared to females $7.6 \%$. Total usage of water only or with soap and medication was $20 \%$ and even further lower in females $15.2 \%$. A $6.7 \%$ said that they should apply medicine at site of bite. Others included applying oil, salt, dressing, leave wound untreated, Dettol which in all was $6.7 \%$.

\section{DISCUSSION}

In our study, maximum number (45\%) of people said that person bitten by animal will go insane; $18 \%$ said animal bite will cause rabies and $15 \%$ said that there will be spread of poison; $21 \%$ did not know what will happen after animal bite.

However, in Agarvval N, et al. ${ }^{4}$ study when asked why the patient will die post animal bite, the major reasons were given as the spread of poison in the body (41\%), insanity (33\%) and absence of treatment (7.6\%).

In our study, $83.9 \% \%$ people knew that the transmission was due to animal bite, which is more than the study done by Lai, et al. ${ }^{5}$ In their study, $61.1 \%$ transmission is by animal bite. In our study transmission by sneezing is $10.9 \%$, which is similar to $12 \%$ as in Lai et al. study. In another study by Eshetu Yimer, et al. $673.4 \%$ of the households replied that rabies can be transmitted through bite, scratch and lick to open wounds. In another study by Prakash M, et al. ${ }^{7}$ all study participants had knowledge as regards transmission of rabies by dog bite, compared to only $23 \%$ having knowledge about its transmission by scratches and licks of a rabid dog.

In this study out of the total males (174) about 83.9\% said that rabies was transmitted by animal bite, $10.3 \%$ by sneezing, $4.1 \%$ does not know the exact mode of transmission. Among the total females (66) about $83.3 \%$ said that rabies were transmitted by animal bite, $12.2 \%$ by sneezing and $3 \%$ does not know the exact mode of transmission and this relation between mode of transmission and sex is found to be statistically insignificant, whereas in a study by Lai $P$, et al. 5 out of total males (98) $56.1 \%$ said that rabies was transmitted through animal bite, $9.2 \%$ by sneezing and $34.7 \%$ did not know about the transmission. Out of total females (28) 78.6\% told animal bite, $10.7 \%$ sneezing and $10.7 \%$ did not know about mode of transmission and this relation was significant.

In our study, $77.7 \%$ respondents said that dog is the animal transmitting rabies followed by monkeys $38.33 \%$, cat $23.75 \%$. In a study by Sekhon AS, et al. 8 transmission by dog was $95 \%$ followed by cat $1.3 \%$, mongoose $1.7 \%$ and monkeys $1.8 \%$. In a study done by Prakash et al. ${ }^{6}$ in response to the question on transmission of rabies by bite of animals other than dog, 17\% responded for cat and 12\% monkey. In a study by Eshetu Yimer, et al. 5 a significant proportion of the interviewed households 2,323 (97.2\%), ( $\mathrm{P}<0.05)$ indicated that they have the knowledge that dogs, cats and other animals can transmit rabies to humans.

The transmission by monkey, cat and mouse and fox was known only to $38.3 \%, 23.7 \%, 6.2 \%, 2.5 \%$ respondents 
respectively, which are considerably low and $14.58 \%$ were still unaware about animal transmitting rabies; $8.74 \%$ have misconception about snake, scorpion, lizard, insects and environmental pollution as cause of rabies transmission, which are not responsible for transmitting rabies.

In our study, $55 \%$ of people agreed to consult doctor and 18.33\% will take Anti-Rabies Vaccine (ARV); $21.66 \%$ people were open to witchcraft, although $8.33 \%$ of these also will consult doctor and $3.75 \%$ will also go for ARV. Agarvval N, et al. ${ }^{4}$ study also showed that after a dog bite, $53 \%$ preferred to visit a health facility. A quarter of the respondents believed that rabies could be treated by injections $(15.2 \%)$, medicines $(5.3 \%)$ and by local healers $(0.8 \%)$. In another study done by Singh US, et al. ${ }^{9} 86.6 \%$ of individuals were aware about antirabies vaccine and $24.4 \%$ knew that pet dogs need vaccine against rabies; $31.1 \%$ would like to apply first aid measure and $36.4 \%$ will visit to doctor and rest either do nothing or adopt some religious practices to prevent the development of rabies; $86.6 \%$ of individuals were aware about anti-rabies vaccine and $24.4 \%$ knew that pet dogs need vaccine against rabies.

In our study, management of animal bite was compared among various educational status groups. People's perception regarding management of animal bite with witchcraft is higher in lower educational status Witchcraft in illiterate and up to primary was $43.5 \%$ each, witchcraft and consult doctor was $42.9 \%$ among illiterate and $33.3 \%$ up to primary. Witchcraft and ARV in illiterate is $22.2 \%$ and up to primary was $44.4 \%$. Management of animal bite by consulting doctor or by ARV was seen among all education groups, although higher percentage was seen in lower education groups. No such comparable study could be found.

In our study, $57 \%$ respondents suggested applying chilli and turmeric at the site of bite; $10.8 \%$ were having adequate knowledge of washing the wound with water and soap, $6.7 \%$ answered applying medicine at the site of wound. As per Sekhon AS, et al. ${ }^{7}$ common practices prevalent in the management of wounds were washing with soap and water $(21.02 \%)$ with only water $(9.53 \%)$, application of chillies (14.18\%), Dettol and antiseptic (5.45\%), cowdung (0.46\%) and carbon (0.89\%). Agarvval N, et al. ${ }^{3}$ study also showed that after a dog bite $42.4 \%$ relied on household treatments like putting chilly on wound, preferably procured from the house of the dog owner. In a study conducted by Kakrani VA, et al. ${ }^{9}$ $82 \%$ believed that cowdung, while $60 \%$ felt that leaves can be applied at the wound following dog bite. As per study by Shah Venu et al. ${ }^{10}$ only 277 (24.9\%) had done the wound washing after the bite. Half of the cases $(52.6 \%)$ had applied indigenous materials on the wound, $24.9 \%$ washed with water, $13.2 \%$ applied antiseptic cream, $6.7 \%$ did not took any first AID and only $2.6 \%$ had consulted doctor.

In the present study among both male (55.7\%) and female $(63.6 \%)$ still believed in applying chilli and turmeric at the wound site. In a study by Lai P, et al. ${ }^{4}$ among 98 males $(8.1 \%)$ still believed in home remedy and among 28 females (28.5\%) and out of total (126) respondents $12.7 \%$ believed in home remedy, which is less than our study in which application of chilli and turmeric is $57.9 \% ; 10.8 \%$ were having adequate knowledge of washing the wound with water and soap, though males (12.1\%) had higher knowledge compared to females $(7.6 \%)$. In a study by Lai P, et al. ${ }^{4}$ out of total 98 males, $53.5 \%$ said that the wound should be washed with soap and water, whereas out of 28 females $53.5 \%$ said washing the wound with soap and water. In another study by Sekhon AS, et al. ${ }^{7} 21.02 \%$ said that wound should be washed with soap and water. In our study, $6.7 \%$ said that they should apply medicine at site of bite. Others which were $6.7 \%$ included applying oil, salt, dressing, leave wound untreated, Dettol.

\section{CONCLUSION}

Our study indicated that the knowledge about the animal bites and its effects was reasonably known. As far as animal transmitting rabies, there is still inappropriate knowledge. Large number of people knew that rabies can be prevented by consulting doctor and the usage of Anti Rabies Vaccine, but still old beliefs and practices exist in the community as majority of people believe in applying red chillies, turmeric, salt, etc. to the bite wound. Thus there is immediate need for the policy changes including field workers trainings as they are the key persons who can provide proper knowledge through Information Education and Communication (IEC) materials or Interpersonal Communication (IPC) for appropriate management of animal bite.

\section{REFERENCES}

1. Debbie, JG (1988). WH Forum 9(4):536.

2. WHO (2010). Weekly Epidemiological Record No. 32, 6 ${ }^{\text {th }}$ August, 2010.

3. Agarvval N and Reddaiah VP. Knowledge, attitude and practice following dog bite: a community base epidemiological study. Health and Population. Perspectives and Issues 2002;26(4):154-61.

4. Lai P, Rawat A, Sagar A, et al. Prevalence of dog bites in Delhi: knowledge and practices of residents regarding prevention and control of rabies. Health and Population. Perspectives and Issues 2005;28(2):50-57.

5. Eshetu Yimer, Arthuro Mesfin, Mekoro Beyene, et al. Study on knowledge, attitude and dog ownership patterns related to rabies prevention and control in Addis Ababa, Ethiopian Health and Nutrition Research Institute, P.O. Box 1242/5654, Addis Ababa Region Agricultural Bureau*Corresponding author: e-mail esyima_n@yahoo.com.

6. Prakash M, Bhatti VK, Venkatesh G. Rabies menace and control-an insight into knowledge, attitude and practices. Med J Armed Forces India. Year 2013;69(1):57-60. Jan 2013. Published online Dec 1, 2012.

7. Sekhon AS, Singh Amarjit, Kaur Paramjit, et al. Misconceptions and myths in the management of animal bite cases. IJCM Year:2002, Volume:27, Issue:1, Jan-Mar, Page 9-11.

8. Sekhon AS, Singh A, Kaur P, et al. Misconceptions and myths in the management of animal bite cases. IJCM Year 2002, Volume:27, Issue:1, Jan-Mar, Page 9-11.

9. Kakrani VA, Jethani S, Bhawalkar J. Awareness about dog bite management in rural population. IJCH Year 2013, Vol:25, No:3, July-Sep 2013.

10. Shah V, Bala DV, Thakker J, et al. Epidemiological determinants of animal bite cases attending the antirabies clinic at V S General Hospital, Ahmedabad, Dept of Community Medicine, Smt NHL Municipal Medical College, Ahmedabad. Healthline Volume:3, Issue:1, January-June 2012. 